\title{
The endless quest for an ideal bioprosthetic valve
}

\author{
Ko Bando, MD, PhD
}

\author{
From the Department of Cardiac Surgery, The Jikei University School of Medicine, Tokyo, Japan. \\ Disclosures: Author has nothing to disclose with regard to commercial support. \\ Received for publication July 12, 2016; accepted for publication July 12, 2016; available ahead of print Aug 24, \\ 2016. \\ Address for reprints: Ko Bando, MD, PhD, Department of Cardiac Surgery, The Jikei University School of \\ Medicine, 3-25-8 Nishi Shinbashi, Minato-ku, Tokyo, 105-8461 Japan (E-mail: kobando@ jikei.ac.jp). \\ J Thorac Cardiovasc Surg 2016;152:1299-300 \\ $0022-5223 / \$ 36.00$ \\ Copyright (c) 2016 by The American Association for Thoracic Surgery \\ http://dx.doi.org/10.1016/j.jtcvs.2016.07.032
}

Although the introduction of transcatheter aortic valve replacement has advanced the strategy for treatment of patients with severe aortic stenosis who are at high risk or are not operative candidates, ${ }^{1}$ surgical aortic valve replacement remains the criterion standard as a treatment modality for patients with severe aortic stenosis. ${ }^{2}$ Bioprostheses are recommended for geriatric patients who are older than 65 years and require surgical aortic valve replacement. During the last 40 years, there has been an ongoing evolution of device designs with the aim of better performance characteristics, including a larger aortic valve area, a lower pressure gradient, and improved durability.

The Trifecta bioprosthesis (St Jude Medical, Inc, St Paul, Minn) is a third-generation trileaflet, titanium-stented pericardial valve designed for supra-annular implantation in the aortic position. ${ }^{3}$ This valve is engineered such that the externally mounted pericardial tissue creates a larger orifice area. Unlike Ionescu-Shiley valves, the stent of the Trifecta valve, with the exception of the sewing ring, is completely covered with porcine pericardium, thereby minimizing wear and tear while only allowing tissue-to-tissue contact during the opening and closing of the valve.

In this issue of The Journal of Thoracic and Cardiovascular Surgery, Rubens and colleagues ${ }^{4}$ compare the outcomes of patients with aortic stenosis and left ventricular hypertrophy who underwent aortic valve replacement with either the Trifecta or the Primount Magna Ease (Edwards Lifesciences, Irvine, Calif), with a focus on left ventricular (LV) mass regression, all-cause mortality, and morbidity, including readmission and congestive heart failure. ${ }^{4}$ Although previous articles have reported on postoperative hemodynamic performance variables, including pressure gradient, effective orifice area, and indexed effective orifice area, and on patientprosthesis mismatch (PPM), this study represents the first report documenting serial LV mass regression with time by adjusting for the propensity scores and operative characteristics according to a repeated measures growth curve model. This study also represents one of the earliest studies that has demonstrated a clinical advantage of the Trifecta valve relative to the Magna Ease valve in terms of freedom from congestive heart failure, cardiac readmission, and the

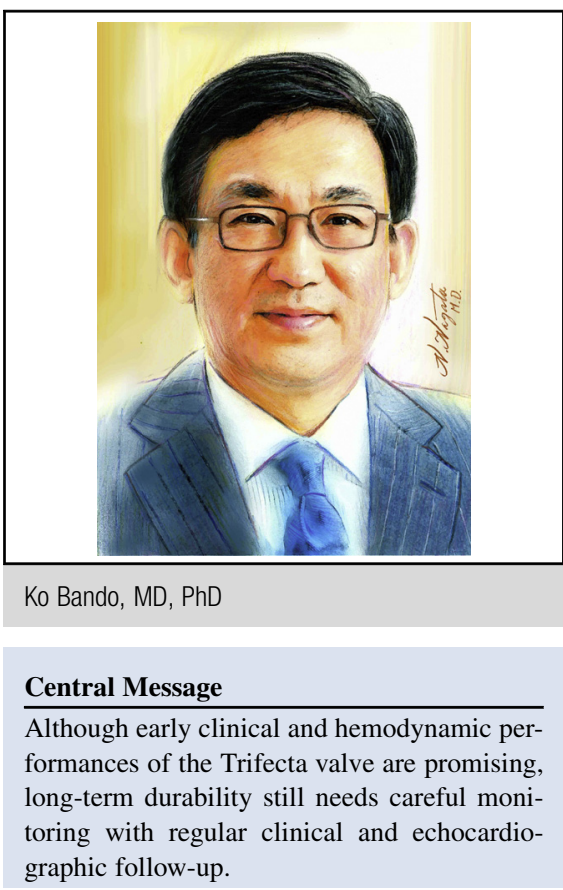

See Article page 1291.

combined end point of mortality and freedom from the previously described morbidity. I congratulate Rubens and colleagues ${ }^{4}$ on their well-organized, large-scale, single-center, retrospective study and its sophisticated use of statistics.

Durability and hemodynamic performance of bioprosthetic valves both depend on the design of the prosthesis and the implantation technique. Because a Trifecta valve has a longer height and a larger replica size compared to other bioprosthetic valves, care must be taken never to oversize it, because oversizing can cause titanium deformation. ${ }^{5}$ Indeed, one of the rare early failures of a Trifecta aortic bioprosthesis was related to the height of this particular valve and deformity of the titanium stent, ${ }^{6}$ because low aortotomy combined with a small Valsalva sinus resulted in a tightly attached valve stent to the Valsalva sinus, which caused the development of severe intraprosthetic aortic regurgitation.

The appropriate suture technique for this particular bioprosthetic valve is also a matter of debate. A recent study by Tabata and coworkers ${ }^{7}$ has suggested that an interrupted unpledgeted suture technique may be associated with a lower incidence of PPM because of a relatively larger increase in effective orifice area, ${ }^{7}$ whereas the Mayo Clinic group has indicated that the suture technique does not affect hemodynamic performance of the small supra-annular Trifecta bioprosthesis. ${ }^{8}$ The use of simple sutures may be 
advantageous, because such a technique does not require felt pledgets or multiple knots, which can increase the risk of thrombus and embolus formation. On the other hand, pledget-reinforced mattress sutures may decrease the risk of paravalvular leakage relative to simple sutures. Long-term echocardiographic follow-up is necessary to detect any such valve-related events.

Although the impact of PPM on aortic valve replacement has been debated for longer than 4 decades, several authors have concluded that it is an important predictor of late morbidity and mortality, especially in the younger generation and in patients with reduced left ventricular function, whereas it may not have a major impact in the geriatric population. ${ }^{9}$ The studies of Rubens and colleagues ${ }^{4}$ and others $^{10,11}$ indicate that Trifecta valves have been more frequently implanted in patients with a small aortic annulus as compared to other types of bioprosthetic valve and that severe PPM has very rarely been encountered when Trifecta valves are implanted in patients with a small annulus. A steady decline in LV mass index observed after Trifecta valve implantation relative to Magna Ease valves during a period of 240 days ${ }^{4}$ provides strong evidence to assure us of the superior hemodynamic performance of this particular valve. Further precise analyses are necessary to determine whether these hemodynamic advantages are primarily seen among patients with a small aortic valve annulus or whether they occur at all annular sizes.

Moreover, postoperative medical treatment may have a significant impact on the degree of LV mass regression. In a multi-institutional study group, Helder and associates ${ }^{12}$ indicated that the postoperative administration of either $\beta$-blockers or calcium-channel blockers at discharge predicted complete LV mass regression. The length of time that it takes to achieve complete LV mass regression after surgery, however, and also how to promote and maintain this regression, still need to be determined.

The excellent article by Rubens and colleagues ${ }^{4}$ from the Ottawa Heart Institute certainly provides solid evidence of superb early clinical and hemodynamic performance of the Trifecta valve as late as 2 years after surgery. Longterm durability, however, still needs to be monitored carefully. Regular clinical and echocardiographic followup observations are therefore mandatory. We must avoid repeating the unfortunate experience with Ionescu-Shiley valves (Shiley Incorporated, Irvine, Calif), which resulted in leaflet tears in the majority of cases. ${ }^{13,14}$ The endless quest for an ideal bioprosthetic valve continues.

\section{References}

1. Smith CR, Leon MB, Mack MJ, Miller DC, Moses JW, Svensson LG, et al; PARTNER Trial Investigators. Transcatheter versus surgical aortic-valve replacement in high-risk patients. N Engl J Med. 2011;364:2187-98.

2. Reinöhl J, Kaier K, Reinecke H, Schmoor C, Frankenstein L, Vach W, et al. Effect of availability of transcatheter aortic-valve replacement on clinical practice. N Engl J Med. 2015;373:2438-47.

3. Bavaria JE, Desai ND, Cheung A, Petracek MR, Groh MA, Borger MA, et al. The St Jude Medical Trifecta aortic pericardial valve: results from a global, multicenter, prospective clinical study. J Thorac Cardiovasc Surg. 2014;147: 590-7.

4. Rubens FD, Gee YY, Ngu JM, Chen L, Burwash IG. Effect of aortic pericardial valve choice on outcomes and left ventricular mass regression in patients with left ventricular hypertrophy. J Thorac Cardiovasc Surg. 2016;152:1291-8.

5. Jamieson WR. St Jude Medical Trifecta aortic prosthesis: considerations for implantation. J Thorac Cardiovasc Surg. 2015;149:1576-7.

6. Campisi S, Camilleri L, Innorta A, Azarnoush K. Early failures of Trifecta aortic bioprosthesis. J Thorac Cardiovasc Surg. 2014;148:e133-4.

7. Tabata M, Shibayama K, Watanabe H, Sato Y, Fukui T, Takanashi S. Simple interrupted suturing increases valve performance after aortic valve replacement with a small supra-annular bioprosthesis. J Thorac Cardiovasc Surg. 2014; $147: 321-5$.

8. Ugur M, Byrne JG, Bavaria JE, Cheung A, Petracek M, Groh MA, et al. Suture technique does not affect hemodynamic performance of the small supra-annular Trifecta bioprosthesis. J Thorac Cardiovasc Surg. 2014;148:1347-51.

9. Moon MR, Pasque MK, Munfakh NA, Melby SJ, Lawton JS, Moazami N, et al. Prosthesis-patient mismatch after aortic valve replacement: Impact of age and body size on late survival. Ann Thorac Surg. 2006;81:481-8; discussion 489.

10. Wendt D, Thielmann M, Plicht B, Aßmann J, Price V, Neuhäuser M, et al. The new St Jude Trifecta versus Carpentier-Edwards Perimount Magna and Magna Ease aortic bioprosthesis: is there a hemodynamic superiority? J Thorac Cardiovasc Surg. 2014;147:1553-60.

11. Deutsch MA, Prinzing A, Fiegl K, Wottke M, Badiu CC, Krane M, et al. Early haemodynamic performance of a latest generation supra-annular aortic bioprosthesis: experience from a large single-centre series. Euro J Cardiothorac Surg. 2016;49:1691-8.

12. Helder MR, Ugur M, Bavaria JE, Kshettry VR, Groh MA, Petracek MR, et al. The effect of postoperative medical treatment on left ventricular mass regression after aortic valve replacement. J Thorac Cardiovasc Surg. 2015;149:781-6.

13. Walley VM, Keon CA, Khalili M, Moher D, Campagna M, Keon WJ. IonescuShiley valve failure. I: experience with 125 standard-profile explants. Ann Thorac Surg. 1992;54:111-6.

14. Walley VM, Keon CA, Khalili M, Moher D, Campagna M, Keon WJ. IonescuShiley valve failure. II: experience with 25 low-profile explants. Ann Thorac Surg. 1992;54:117-22; discussion 122-3. 